\title{
Survey of the Injury Rate for Children in Community Sports
}

\author{
Marirose A. Radelet, MS, PT, ATC*; Scott M. Lephart, PhD, ATC*; Elaine N. Rubinstein, PhD ; and \\ Joseph B. Myers, PhD, ATC*
}

\begin{abstract}
Objective. To determine the baseline injury rate for children ages 7 to 13 participating in community organized baseball, softball, soccer, and football.

Methods. In this observational cohort study, 1659 children were observed during 2 seasons of sports participation in an urban area. Data were collected by coaches using an injury survey tool designed for the study. A reportable injury was defined as one requiring on-field evaluation by coaching staff, or causing a player to stop participation for any period of time, or requiring first aid during an event. Logistic regression analyses were done within and across sports for injury rates, game versus practice injury frequencies, and gender differences where appropriate.
\end{abstract}

Results. The injury rates, calculated per 100 athlete exposures during total events (games plus practices), were: baseball, 1.7; softball, 1.0; soccer, 2.1; and football, 1.5. The injury rates for baseball and football were not significantly different. Across sports, contusions were the most frequent type of injury. Contact with equipment was the most frequent method of injury, except in football where contact with another player was the most frequent method. In baseball, $3 \%$ of all injuries reported were considered serious (fracture, dislocation, concussion); in soccer, $1 \%$ were considered serious; and in football, $14 \%$ were considered serious. The frequency of injury per team per season (FITS), an estimation of injury risk, was 3 for baseball and soccer, 2 for softball, and 14 for football for total events. For all sports, there were more game than practice injuries; this difference was significant except for softball. There were no significant gender differences in soccer for injury rates during total events.

Conclusions. Given the classification of football as a collision sport, the high number of exposures per player, the FITS score, and the percentage of injuries considered serious, youth football should be a priority for injury studies. Health professionals should establish uniform medical coverage policies for football even at this age level.

Recommendations for Modifications. Injury surveillance for youth sports is gaining momentum as an important step toward formulating injury prevention methods. However, establishing patterns of injuries, taking preventive measures, and evaluating equipment and coaching modifications may take years. In addition to the objective findings of this study, our direct observations of community sports through 2 seasons showed areas

From the ${ }^{*}$ Neuromuscular Research Laboratory and $\ddagger$ Office of Measurements and Evaluation of Teaching, University of Pittsburgh, Pittsburgh, Pennsylvania.

Received for publication Nov 30, 2001; accepted Apr 17, 2002.

Reprint requests to (S.M.L.) Neuromuscular Research Laboratory, $3200 \mathrm{~S}$ Water St, Pittsburgh, PA 15203. E-mail: neurolab@pitt.edu

PEDIATRICS (ISSN 0031 4005). Copyright @ 2002 by the American Academy of Pediatrics. where immediate modifications could reduce injury risk. The first recommendation is that youth sports leagues provide and require first aid training for coaches. Training could be done by sports medicine professionals and include recognition and immediate response to head, neck, and spine injuries, as well as heat-related illnesses. The second recommendation is that youth sports leagues have clear, enforceable return to play guidelines for concussions, neck and back injuries, fractures, and dislocations. The third recommendation is that baseball and softball leagues consider the injury prevention potential of face guards on batting helmets. Pediatrics 2002;110(3). URL: http://www.pediatrics.org/cgi/content/full/110/3/ e28; first aid training, injury risk, injury prevention, gender differences.

ABBREVIATIONS. AE, athlete exposure; FITS, frequency of injury per team per season.

$\mathrm{E}$ ach year in the United States, an estimated 20 to 30 million youths between 5 and 17 years of age participate in community-sponsored athletic programs. ${ }^{1-4}$ The number of injuries reported for this age group has increased proportional to participation and has become a concern of pediatric and sports medicine professionals.

Young athletes are vulnerable to different injuries than adults, including microtrauma to growth cartilage and macrotrauma at apophyses and growth plates. In children, ages 5 to 13 , and adolescents, ages 13 to 17 , intrinsic injury risk factors, which change relatively slowly, include physiologic, developmental, and psychological components. Skeletal immaturity in children and adolescents is signified by the presence of growth cartilage at epiphyseal plates, at the articular cartilage of joint surfaces, and at apophyses where muscle tendon units insert into bone. ${ }^{2}$ Acute and overuse injuries involving growth cartilage may seem to be minor but may cause permanent alteration of bone growth with long-term disability as a consequence if they are ignored. ${ }^{2,5}$ Biomechanically, the issues of joint laxity/tightness, differential growth rates of bone and soft tissue, and the changing characteristics of bone density and stiffness and muscle tendon imbalance can be significant contributing factors to injury as children progress through adolescence. ${ }^{6-8}$ Developmental and psychological immaturity must also be taken into account as intrinsic injury risk factors for this age group. ${ }^{6}$

In youth sports, extrinsic injury factors, which change frequently, include environmental, training and equipment conditions, and parental influences. 
Coaches, the true backbone of community sports leagues, are usually volunteers who do not have formal training and who base their coaching techniques on their own personal experiences. ${ }^{9}$ Their absolute zeal for the game sometimes leads them, as well as the parents of their players, to emphasize the competitive rather than the skill and enjoyment aspects of the sport. ${ }^{9,10}$ Equipment availability, condition, and required use vary widely within and across sports. $2,6,7,9,11-13$

During the past 4 decades, adolescents (ages 1317 ) and young adults (ages 18-24) who participate in high school and college sports have been the main focus of injury surveillance systems such as the National Athletic Injury/Illness Reporting Systems, ${ }^{14}$ the National High School Injury Registry, ${ }^{15}$ the North Carolina High School Athletic Injury Study, ${ }^{16}$ the Pennsylvania Injury Reporting System, ${ }^{17}$ and numerous others.

The perception that children who participate in organized sports have fewer and less severe acute and overuse injuries than adolescents persists, but there have been few studies done to investigate injury rates, frequencies, and severity for this age level. The majority of previous studies of injuries to children and adolescents during sports participation used subjects in school settings. ${ }^{18-22}$ Many collected retrospective injury data from emergency department or physician office visits $18,20,21$ or used insurance claim data. ${ }^{23}$ Reportable injuries in the majority of the larger studies for this age group included all sources of injury with sports injuries as a subset, ${ }^{20,24}$ or grouped team sports and individual recreational activities such as bicycle and skateboard riding, ${ }^{18,20,21}$ or considered only specific injury categories such as concussion. ${ }^{25}$ The definition of injury for each of these studies also differed.

The purpose of this prospective study was to determine the baseline injury rate for 7- to 13-year-old children who participated in community organized baseball, softball, soccer, and football in the greater Pittsburgh area throughout 2 seasons of organized youth sports as reported by coaches and by direct observation of researchers. The frequency and severity of injuries, anatomic injury sites, and gender differences were also tracked when appropriate.

\section{METHODS}

\section{Experimental Design}

This study used a prospective observational cohort format and was approved by the Institutional Review Board at the University of Pittsburgh. Because there was no direct contact with players or interference with their participation during the season, the institutional review board waived the need for consent forms for this study.

\section{Sports}

All sports included in this study drew their players from a single urban area. Each sport had specific guidelines for age and/or weight requirements for teams, 10- to 12-week regular seasons, and "everybody plays at every event" rules. Across sports, coaches were volunteers from the community. The pattern of games and practices differed across sports. Football was the only sport that had more practices than games. For football, scrimmages were counted as games.

\section{Subjects}

A total of 1659 children ages 7 to 13 were observed during the 1999 and 2000 seasons. Although no league rules mandated this, baseball participants all were boys and softball registered all girls with 1 or 2 exceptions. Football teams were all boys. Soccer fielded separate boys' and girls' teams for fall and spring leagues but had mixed teams for the indoor league. Each baseball/softball team had 10 to 15 players, soccer teams each fielded 9 to 11 players, and football registered 30 to 45 players per team.

\section{Instruments}

The model for surveillance systems has been well defined with the rate of injury per athlete exposure (AE) being the key data descriptor. ${ }^{16,26-31} \mathrm{AE}$ or participation is defined as 1 athlete participating in 1 event (game or practice). Using the strengths of previous surveillance systems as a guide, we designed 2 tools: 1 ) an injury survey form (Fig 1) that allowed injury reporting for multiple games and practices in a check-off format and 2) a team roster form (Fig 2) to record team demographic data.

The injury survey and team roster forms were pretested during the 1999 season with 9 baseball and 6 soccer teams. Format changes were made incorporating coach suggestions for reporting. Preliminary data analysis suggested minor changes to the forms for clarification purposes.

\section{Primary Data Collectors}

We selected coaches as the primary data collectors because they were present at all practices and games, had experience within the sport, and were the observer most likely to remain objective when injuries occurred.

\section{Definition of Injury}

The definition of injury was broad to capture maximum data for this baseline study. A reportable injury was defined as an injury that brought a coach onto the field to check the condition of a player, or one in which a player was removed from participation, or one in which a player needed any type of first aid during an event.

\section{Procedures}

We approached the governing organization for each sport for permission to conduct the study with league-level support and active promotion. We believed that support at the league level would increase reporting compliance and coach participation within sports. Once we received endorsement from the leagues, we presented the study rationale and description to representatives from each of the neighborhood associations within the sport. The association presidents or commissioners chose from their groups team coaches who would participate. Before the season started, we instructed participating coaches about data collection procedures, the definition of injury, and methods of weekly reporting.

\section{Data Collection}

We contacted coaches weekly throughout the season by telephone, by e-mail, or in person to collect team data, to resolve questions, and to encourage reporting compliance. Coaches could also return survey forms by mail with postage reimbursed or on line.

We entered injury data weekly onto a league database. We attended games and practices throughout the season for each sport to record injury data for teams whose coaches did not participate in the study on a regular basis and to check the accuracy of data from reporting coaches at those games. Comparison of coach-reported/researcher-reported data for the same events across the study would have helped assess the accuracy of coachreported data. However, such analysis was beyond the scope of this study.

\section{Incentives}

To encourage compliance further, we offered incentives to leagues, neighborhood associations, and coaches. During the season, we conducted information sessions for coaches on safety topics specified by the league. After the study was completed, leagues received a sports-specific report including injury rates, 


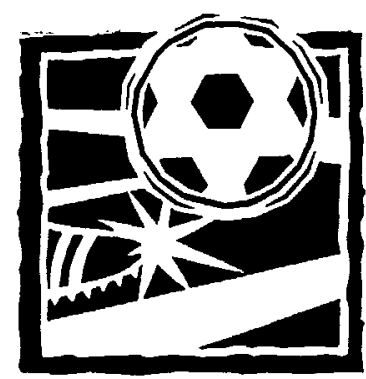

Injury

Survey

Fill out at least one column for each game and practice even if there are no injuries. Use a separate column for each injury.

An injury is defined as:

- any event that brings a player off the field or

- brings any member of the coaching staff onto the field to check a player during a game/practice or

- requires first aid at any time during a game or practice.

\section{Multiple absences}

due to injury.

Is there a player on your team who has been kept out of games or practices due to an injury? Please list their unique initials below.

$\begin{array}{ll}\text { unique } & \text { \#games/practices } \\ \text { initials } & \text { missed }\end{array}$

Questions or problems?

Call Marirose Radelet at

(412) $322-1188$

Fax/send completed survey pages at the end of each week. Fax to (412) 322-2667 Send to: 1246 Resaca Place Pittsburgh, PA 15212

or e-mail information weekly to marst92+@pittedu
Coach:

\begin{tabular}{|c|c|c|c|c|c|c|c|}
\hline \multicolumn{2}{|r|}{ \# of players participating } & & & & & & \\
\hline \multirow[b]{3}{*}{ Injury } & \multirow{2}{*}{$\begin{array}{l}\text { Game-G OR Practice-P } \\
\text { (arcle one) } \\
\text { no injuries }\end{array}$} & $G P$ & & $G P$ & $G P$ & $G P$ & $G P$ \\
\hline & & $\square$ & $\square$ & $\square$ & $\square$ & $\square$ & $\square$ \\
\hline & \multicolumn{7}{|l|}{$\begin{array}{l}\text { Injured player } \\
\text { (Unique intials) }\end{array}$} \\
\hline Head & $\begin{array}{r}\text { head } \\
\text { eye } \\
\text { ear } \\
\text { face } \\
\text { mouth } \\
\text { neck }\end{array}$ & $\begin{array}{l}\square \\
\square \\
\square \\
\square \\
\square \\
\square\end{array}$ & $\begin{array}{l}\square \\
\square \\
\square \\
\square \\
\square \\
\square\end{array}$ & $\begin{array}{l}\square \\
\square \\
\square \\
\square \\
\square \\
\square\end{array}$ & $\begin{array}{l}\square \\
\square \\
\square \\
\square \\
\square \\
\square\end{array}$ & $\begin{array}{l}\square \\
\square \\
\square \\
\square \\
\square \\
\square\end{array}$ & $\begin{array}{l}\square \\
\square \\
\square \\
\square \\
\square \\
\square\end{array}$ \\
\hline Torso & $\begin{array}{r}\text { back } \\
\text { chest } \\
\text { stomach }\end{array}$ & $\begin{array}{l}\square \\
\square \\
\square\end{array}$ & $\begin{array}{l}\square \\
\square \\
\square\end{array}$ & $\begin{array}{l}\square \\
\square \\
\square\end{array}$ & $\begin{array}{l}\square \\
\square \\
\square\end{array}$ & $\begin{array}{l}\square \\
\square \\
\square\end{array}$ & $\begin{array}{l}\square \\
\square \\
\square \\
\end{array}$ \\
\hline Arm & $\begin{array}{r}\text { shoulder } \\
\text { upper arm } \\
\text { elbow } \\
\text { lower arm } \\
\text { wrist } \\
\text { hand } \\
\text { fingers }\end{array}$ & $\begin{array}{l}\square \\
\square \\
\square \\
\square \\
\square \\
\square \\
\square\end{array}$ & $\begin{array}{l}\square \\
\square \\
\square \\
\square \\
\square \\
\square \\
\square\end{array}$ & $\begin{array}{l}\square \\
\square \\
\square \\
\square \\
\square \\
\square \\
\square\end{array}$ & $\begin{array}{l}\square \\
\square \\
\square \\
\square \\
\square \\
\square \\
\square\end{array}$ & $\begin{array}{l}\square \\
\square \\
\square \\
\square \\
\square \\
\square \\
\square\end{array}$ & $\begin{array}{l}\square \\
\square \\
\square \\
\square \\
\square \\
\square \\
\square\end{array}$ \\
\hline Leg & $\begin{array}{r}\text { hip } \\
\text { thigh } \\
\text { knee } \\
\text { shin } \\
\text { calf } \\
\text { ankle } \\
\text { foot } \\
\end{array}$ & $\begin{array}{l}\square \\
\square \\
\square \\
\square \\
\square \\
\square \\
\square\end{array}$ & $\begin{array}{l}\square \\
\square \\
\square \\
\square \\
\square \\
\square \\
\square\end{array}$ & $\begin{array}{l}\square \\
\square \\
\square \\
\square \\
\square \\
\square \\
\square\end{array}$ & $\begin{array}{l}\square \\
\square \\
\square \\
\square \\
\square \\
\square \\
\square\end{array}$ & $\begin{array}{l}\square \\
\square \\
\square \\
\square \\
\square \\
\square \\
\square\end{array}$ & $\begin{array}{l}\square \\
\square \\
\square \\
\square \\
\square \\
\square \\
\square\end{array}$ \\
\hline Special & $\begin{array}{l}\text { numbness/tingling } \\
\text { (please specify location) }\end{array}$ & $\square$ & $\square$ & $\square$ & $\square$ & $\square$ & $\square$ \\
\hline \multicolumn{8}{|c|}{ Caused by } \\
\hline Contact & $\begin{array}{l}\text { with ground } \\
\text { with another player } \\
\text { with equipment }\end{array}$ & $\begin{array}{l}\square \\
\square \\
\square\end{array}$ & $\begin{array}{l}\square \\
\square \\
\square\end{array}$ & $\begin{array}{l}\square \\
\square \\
\square\end{array}$ & $\begin{array}{l}\square \\
\square \\
\square\end{array}$ & $\begin{array}{l}\square \\
\square \\
\square \\
\end{array}$ & $\begin{array}{l}\square \\
\square \\
\square \\
\end{array}$ \\
\hline \multicolumn{2}{|c|}{$\begin{array}{r}\text { heat } \\
\text { illness } \\
\text { muscle cramp/spasm } \\
\text { Care general/joint pain }\end{array}$} & $\begin{array}{l}\square \\
\square \\
\square \\
\square \\
\square\end{array}$ & $\begin{array}{l}\square \\
\square \\
\square \\
\square \\
\square\end{array}$ & $\begin{array}{l}\square \\
\square \\
\square \\
\square \\
\square\end{array}$ & $\begin{array}{l}\square \\
\square \\
\square \\
\square \\
\square\end{array}$ & $\begin{array}{l}\square \\
\square \\
\square \\
\square \\
\square\end{array}$ & $\begin{array}{l}\square \\
\square \\
\square \\
\square \\
\square\end{array}$ \\
\hline Care & $\begin{array}{r}\text { clean and bandage } \\
\text { doctor's office } \\
\text { emergency room } \\
\text { ice, wrap } \\
\text { splint/sling } \\
\text { none } \\
\text { other } \\
\text { (please specify) } \\
\text { gory }\end{array}$ & $\begin{array}{l}\square \\
\square \\
\square \\
\square \\
\square \\
\square \\
\square\end{array}$ & $\begin{array}{l}\square \\
\square \\
\square \\
\square \\
\square \\
\square \\
\square\end{array}$ & $\begin{array}{l}\square \\
\square \\
\square \\
\square \\
\square \\
\square \\
\square\end{array}$ & $\begin{array}{l}\square \\
\square \\
\square \\
\square \\
\square \\
\square \\
\square\end{array}$ & $\begin{array}{l}\square \\
\square \\
\square \\
\square \\
\square \\
\square \\
\square\end{array}$ & $\begin{array}{l}\square \\
\square \\
\square \\
\square \\
\square \\
\square \\
\square\end{array}$ \\
\hline & $\begin{array}{r}\text { sprain or strain } \\
\text { dislocation } \\
\text { fracture } \\
\text { bruise } \\
\text { laceration/abrasion } \\
\text { other } \\
\text { (please specify) }\end{array}$ & $\begin{array}{l}\square \\
\square \\
\square \\
\square \\
\square \\
\square\end{array}$ & $\begin{array}{l}\square \\
\square \\
\square \\
\square \\
\square \\
\square\end{array}$ & $\begin{array}{l}\square \\
\square \\
\square \\
\square \\
\square \\
\square\end{array}$ & $\begin{array}{l}\square \\
\square \\
\square \\
\square \\
\square \\
\square\end{array}$ & $\begin{array}{l}\square \\
\square \\
\square \\
\square \\
\square \\
\square\end{array}$ & $\begin{array}{l}\square \\
\square \\
\square \\
\square \\
\square \\
\square\end{array}$ \\
\hline
\end{tabular}

Fig 1. Injury survey tool.

http://www.pediatrics.org/cgi/content/full/110/3/e28 


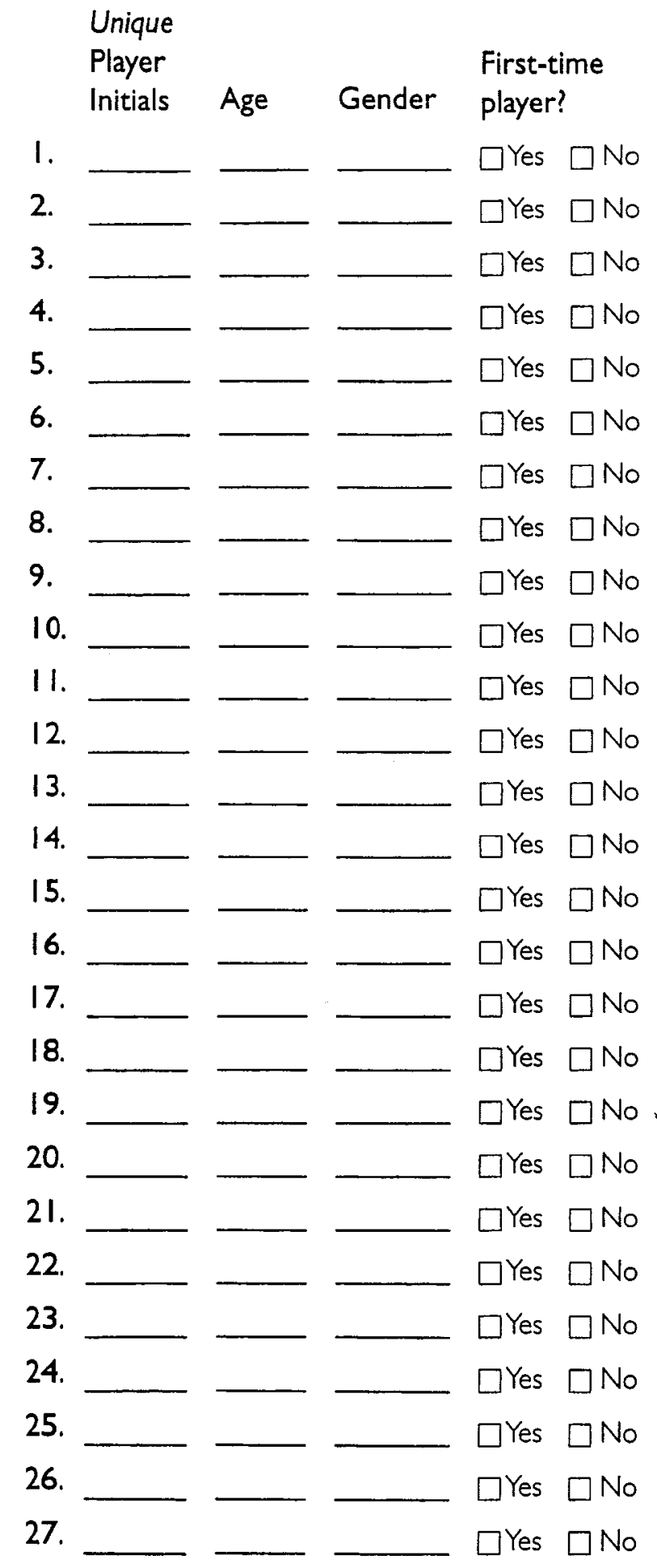

Fig 2. Injury roster form.

frequencies, injury risk analysis, safety recommendations from the researchers, and a summary of safety comments from the coaches. The neighborhood associations for baseball and softball that had the best injury survey response rate received selected new equip-
Coach:

Asst Coach(es):

Length of practices (hrs.):

Length of games (hrs): 
contacts during the season from the researchers and/or league presidents.

\section{Data Analysis}

The injury rate per 100 AEs was calculated within sports for games, practices, and total events (games plus practices). The number of AEs was calculated by aggregating the number of participants for each game or practice ${ }^{25}$ Logistic regression analyses with significance set at $P<.05$ were used to compare injury rates across sports, to compare injury rates in games and practices within each sport, and to compare injury rates between male and female players when appropriate. Ninety-five percent confidence intervals were constructed for injury rates within sports and game versus practice injury frequencies. To present an estimate of injury risk to coaches, parents, and leagues, we calculated the frequency of injury per team per season (FITS) within sports by multiplying the average number of AEs per team per season by the injury rate of the sport. This calculation is similar to John Powell's estimation of injury risk (personal communication, March 28, 2001). Frequencies and percentages were used to summarize anatomic injury sites, response rates, and survey completion information. We arbitrarily set data exclusion levels of 0 injuries with $>200$ AEs per team to compensate for noncompliance with the broad definition of injury. Using this guideline, 3 baseball, 1 football, and 5 softball teams had data excluded from statistical analysis. We used type of injury to indicate severity. Fractures, concussions, and dislocations were considered serious, whereas other types of injuries were considered less serious.

\section{RESULTS}

\section{Results Across Sports}

\section{Athlete Participation and Event Data}

Athlete participation and event data for each sport are shown in Table 1 . The number of players registered to participate in each sport is reported here as a point of interest. The actual number of players who participated in each event as reported on the injury survey was used to calculate AEs. The number of events shows how games and practices were distributed throughout the season for each sport.

\section{Injury Rates}

Injury rates per $100 \mathrm{AE}$, injury frequencies, and $\mathrm{AE}$ data for each sport are shown in Table 2, where sports are grouped as contact (baseball, softball, soccer) or collision (football). Injury rates for all sports in this study population were within the lower and upper boundaries of $95 \%$ confidence intervals as shown in Table 2.

\section{Game Versus Practice Injuries}

Logistic regression analyses showed that for all sports except softball, the odds of being injured during games was significantly greater $(P<.05)$ than the odds of being injured during practices (Table 3 ).

\section{Risk of Injury: FITS}

We calculated the risk of injury within sports by multiplying the average number of AEs per team per

TABLE 1. Athlete Participation and Event Data

\begin{tabular}{lrcccc}
\hline \multicolumn{1}{c}{ Sport } & Teams & Players & Practices & Games & Total Events \\
\hline Baseball & 47 & 534 & 270 & 486 & 756 \\
Softball & 29 & 391 & 216 & 267 & 483 \\
Soccer & 40 & 482 & 265 & 223 & 488 \\
Football & 9 & 252 & 286 & 78 & 364 \\
Totals & 125 & 1659 & 967 & 1054 & 2092 \\
\hline
\end{tabular}

season by the injury rate for that sport. The resulting number represented the FITS, shown in Fig 3. Football, a collision sport, showed a FITS score that was 5 to 7 times higher than the other 3 contact sports. The FITS score for football also reflected the higher average AEs and the greater average number of events per player per season.

\section{Types of Injuries and Care Given}

Data on type of injury and care given across sports are represented in Figs 4 and 5. Across sports, contusions were the most frequent type of injury (54\%). Ice was the most frequent first aid used (27\%), whereas no care was the second most frequent choice for injury care $(26 \%)$ across sports either because no care was needed or because care was not recorded. Figure 6 shows methods of contact injury. The most frequent method of injury for all sports except football was contact with equipment, most often the ball. For football, the most frequent method of injury was contact with another player. The differences between player and equipment contact were significant $(P<$ $.05)$ except in soccer.

\section{Results Within Sports}

Baseball

The injury rate per 100 AEs for baseball was 1.7 for all events (games plus practices), 2.4 for games, and 0.6 for practices. There was a significant difference $(P<.05)$ between game and practice injury rates as shown in Table 3 with injury rates for games greater than for practices. The FITS for baseball was 3 injuries per team per season for total events. The shoulder and hand were the most frequently injured body parts in baseball. The most frequent method of injury was contact with equipment, most often a pitched, hit, or thrown ball. Baseball injuries required 3 ambulance transfers, 8 emergency department visits, and 3 physician office visits. One ambulance transfer resulted in hospitalization. The discharge diagnoses for other emergency department visits were 5 fractures, 1 concussion, 1 dislocation, 1 sprain, and 2 contusions. The physician office visits discharge diagnoses were 3 sprains. Three percent of all reported injuries were considered serious (fracture, dislocation, concussion).

\section{Softball}

For softball, the injury rate per $100 \mathrm{AEs}$ for softball was 1.0 for total events, 1.1 for games, and 0.7 for practices. There was no significant difference in the injury rates between games and practices (Table 3 ). The FITS for softball was 2 for total events. The forearm, wrist, and hand were the most frequently injured body part. There were no emergency department or physician office visits reported for the season and no serious injuries reported.

\section{Soccer}

The injury rate per 100 AEs for all divisions of soccer (indoor, intramural, and travel) was 2.1 for total events, 3.4 for games, and 1.0 for practices. The difference in injury rates between games and prac- 
TABLE 2. Injury Rates per 100 AEs, Injury Frequencies, Exposure Data, and 95\% Confidence Intervals for Injury Rates

\begin{tabular}{|c|c|c|c|c|c|c|c|c|c|c|c|}
\hline \multirow[t]{2}{*}{ Sport } & \multirow{2}{*}{$\begin{array}{l}\text { Practice } \\
\text { Injuries }\end{array}$} & \multirow{2}{*}{$\begin{array}{l}\text { Practice } \\
\text { Exposure }\end{array}$} & \multirow{2}{*}{$\begin{array}{l}\text { P IR Per } \\
100 \text { AEs }\end{array}$} & \multirow{2}{*}{$\begin{array}{l}\text { Game } \\
\text { Injuries }\end{array}$} & \multirow{2}{*}{$\begin{array}{c}\text { Game } \\
\text { Exposure }\end{array}$} & \multirow{2}{*}{$\begin{array}{l}\text { G IR Per } \\
100 \text { AEs }\end{array}$} & \multirow{2}{*}{$\begin{array}{c}\text { Total } \\
\text { Exposure }\end{array}$} & \multirow{2}{*}{$\begin{array}{c}\text { Total } \\
\text { Injuries }\end{array}$} & \multirow{2}{*}{$\begin{array}{l}\text { IR Per } \\
100 \text { AEs }\end{array}$} & \multicolumn{2}{|c|}{ CI for IR } \\
\hline & & & & & & & & & & Lower & Upper \\
\hline Baseball (boys) & 12 & 2113 & 0.6 & $116^{*}$ & 4800 & 2.4 & 6913 & 117 & 1.7 & 1.38 & 2.00 \\
\hline Softball (girls) & 10 & 1445 & 0.7 & 27 & 2362 & 1.1 & 3807 & 37 & 1.0 & 0.66 & 1.28 \\
\hline \multicolumn{12}{|l|}{ Soccer } \\
\hline Boys & 16 & 1587 & 1.0 & 31 & 1212 & 2.6 & 2799 & 47 & 1.7 & & \\
\hline Girls & 9 & 955 & 0.9 & 28 & 682 & 4.1 & 1637 & 37 & 2.3 & & \\
\hline Allt & 25 & 2542 & 1.0 & $75^{*}$ & 2190 & 3.4 & 4732 & 100 & 2.1 & 1.70 & 2.52 \\
\hline Totals & 47 & 8642 & 0.5 & 218 & 11246 & 1.8 & 15452 & 254 & 1.5 & & \\
\hline Football (boys) & 49 & 6611 & 0.7 & $80 *$ & 1851 & 4.3 & 8462 & 129 & 1.5 & 1.26 & 1.78 \\
\hline Totals & 96 & 15253 & 0.6 & 298 & 13097 & 2.1 & 23914 & 383 & 1.5 & & \\
\hline
\end{tabular}

IR indicates injury rate; $P$, practice; $G$, game; $C I$, confidence interval.

* Game injuries significantly greater than practice injuries with $P<.05$.

† Includes indoor soccer, which had mixed boys' and girls' teams.

TABLE 3. Logistic Regression Analysis of Game Versus Practice Injury Rates

\begin{tabular}{lcccccc}
\hline \multicolumn{1}{c}{ Sport } & Coefficient & SE & $\begin{array}{c}\text { Odds } \\
\text { Ratio }\end{array}$ & Significance & \multicolumn{2}{c}{$95 \%$ CI } \\
\cline { 3 - 7 } & & & & & $\begin{array}{c}\text { Lower } \\
\text { Limit }\end{array}$ & $\begin{array}{c}\text { Upper } \\
\text { Limit }\end{array}$ \\
\hline Baseball & 1.46 & 0.32 & 4.32 & .000 & 2.31 & 8.05 \\
Softball & 0.51 & 0.37 & 1.66 & .169 & 0.80 & 3.44 \\
Soccer & 1.27 & 0.23 & 3.57 & .000 & 2.26 & 5.64 \\
Football & 1.8 & 0.18 & 6.05 & .000 & 4.22 & 8.67 \\
\hline
\end{tabular}

SE indicates standard error.

*Significance set at $P<.05$.

tices was significant $(P<.05)$ with injury rates for games greater than for practices. There were no significant gender differences in the injury rates per 100 AEs for teams in the travel league for total events (games plus practices). There were no significant gender differences shown during games only in the intramural league. The FITS for all divisions in soccer was 3 for total events. The face and knee were the most frequently injured body parts in soccer. There were 2 emergency department visits during the season for this age group with discharge diagnoses of 1 fractured wrist and 1 contusion. There was 1 physician office visit with discharge diagnosis of contusion. The percentage of reported injuries that were serious was $1 \%$.

\section{Football}

The injury rate per 100 AEs for football was 1.5 for total events, 4.3 for games, and 0.7 for practices. The difference in injury rates between games and practices was significant $(P<.05)$ with injury rates for games greater than for practices. The FITS for football was 14 for total events. The hand and ankle were the most frequently injured body parts in football. Serious injuries required 1 spine board transfer to the hospital and 4 other ambulance transfers in addition to 9 car transports to emergency department sites. The discharge diagnoses from these visits were 6 fractures, 1 concussion, 4 sprains/strains, and 2 contusions. There were 9 physician office visits reported with discharge diagnoses of 2 fractures, 6 sprains/ strains, and 1 contusion. The percentage of reported injuries that were serious was $13 \%$.

\section{DISCUSSION}

\section{Injury Rates}

In our opinion, the injury rate for each sport in this study seemed to be low, ranging from 1.0 to 2.1 injuries per 100 AEs. We did not find other prospective injury rate studies for children ages 7 to 13 using the same definition of injury and $\mathrm{AE}$ (denominator) criteria for direct comparison. Because the multiple variables that affect injury rates in a given sport were not controlled for the purposes of this study, it is difficult to identify specific reasons for differing rates of injury across sports. It is interesting to note, however, that the speculation that football as a collision sport would have a higher injury rate than the other sports was not supported by the data collected from this study population.

\section{Softball}

The injury rate in softball was lower than in any of the other sports. The nature of the sport and the low injury survey response rate lead to fewer reported injuries. The participating teams used slow-pitch rules in which the ball is pitched underhand in a high arc and reaches home plate and the strike zone on the downward portion of the arc. Softball players had more time to move away from pitched balls than baseball players. Our observation showed that softball practices and games were less intense than baseball or soccer events, with a focus on skills acquisition, not competitiveness. These factors and the low coach participation rate, which is discussed in "Study Limitations," are factors in the low injury rate for the sport. Additional research needs to be done to determine whether the low injury rate in this study population is an artifact of poor reporting compliance or an actual indicator of injury rate for softball for this age group.

\section{Baseball and Softball}

The policy statement on the risk of injury from baseball and softball in children published by the American Academy of Pediatrics ${ }^{32}$ reported that $2 \%$ to $8 \%$ of participants were injured per year and that contusions were the most frequent type of injury. This is comparable to the injury rates found for baseball and softball combined in this study. Contusions were also the most frequent type of injury for both sports reported for this study population. 


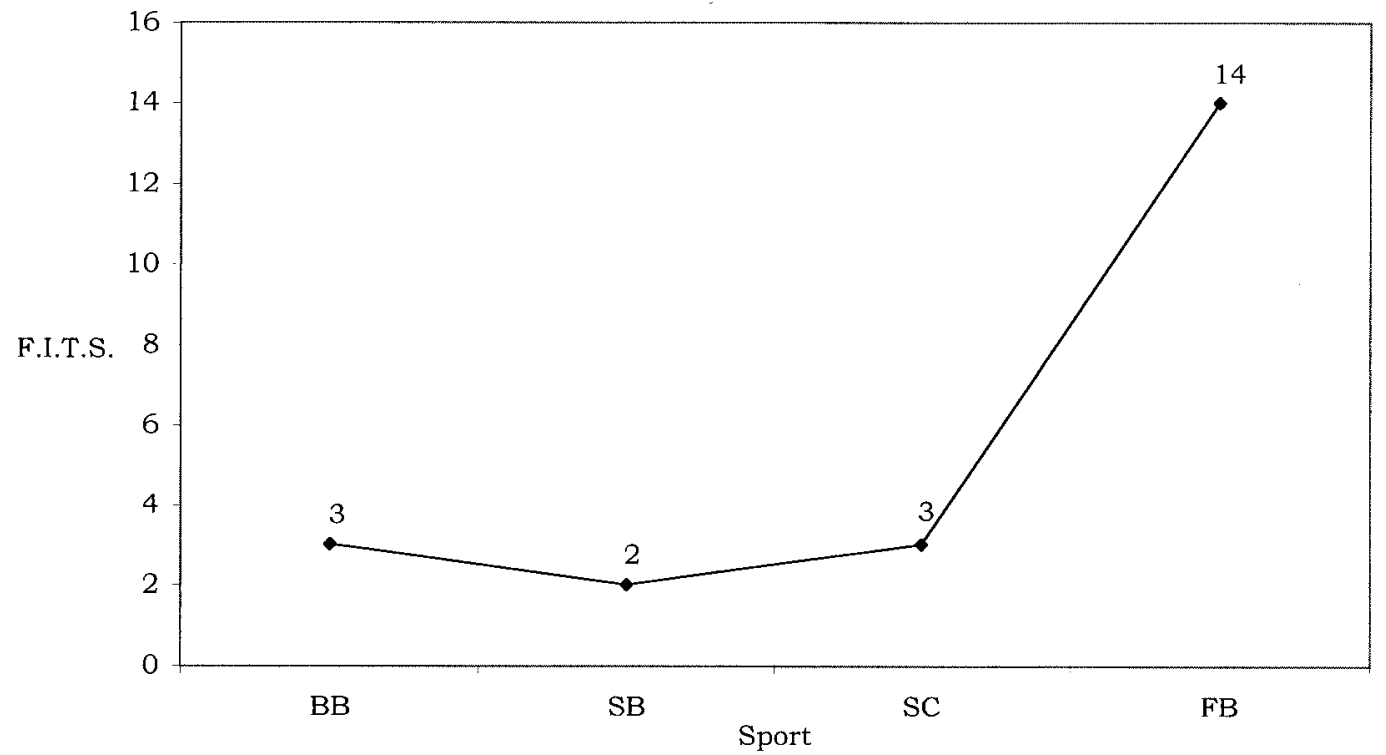

Fig 3. FITS scores.

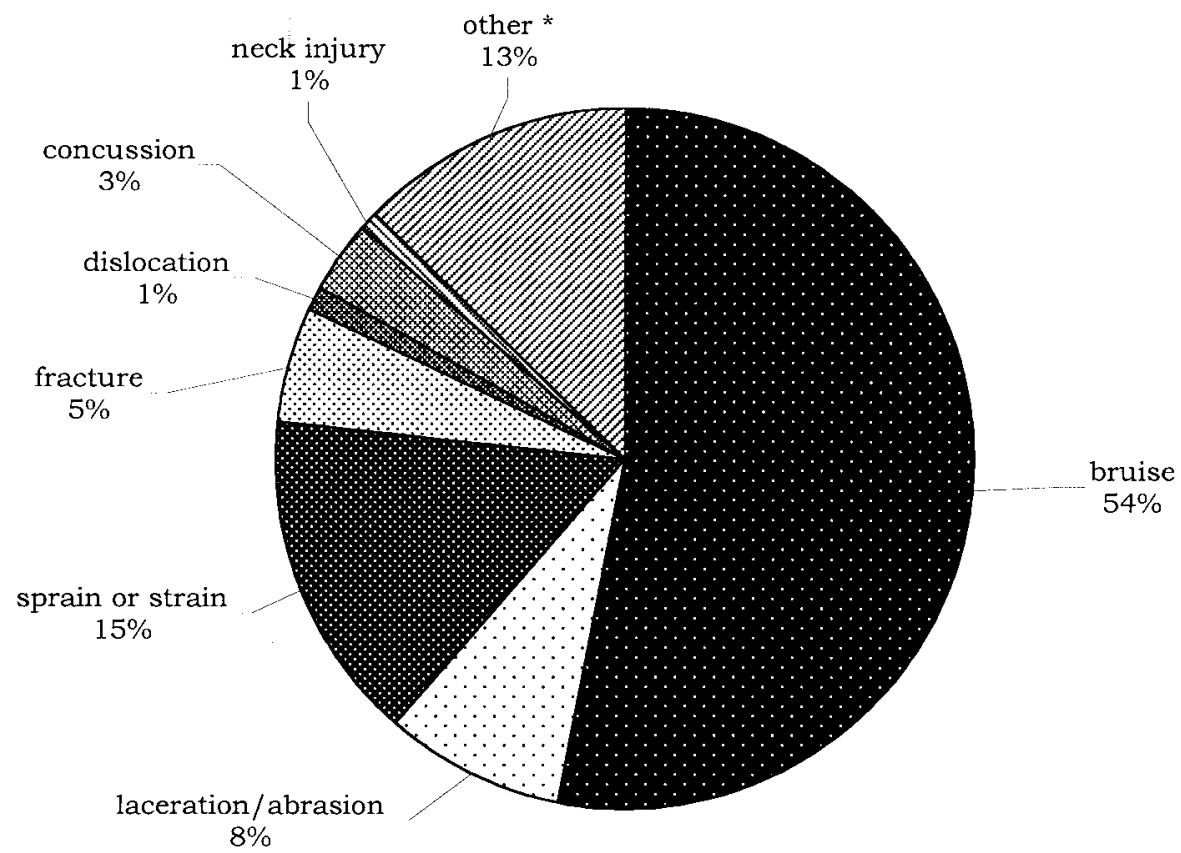

* bee sting, dirt in eye, muscle spasm,winded, exhaustion, heat, groin kick, bloody nose

Fig 4. Type of injury across sports.

\section{Baseball and Football}

Logistic regression analysis showed that the injury rates for baseball and football were not significantly different, with baseball having a higher injury rate than football (Table 2). The high number of injuries from equipment contact in baseball (Fig 5), a better definition-of-injury compliance from baseball coaches, and underreporting of injuries in football could account for the similarity in injury rates between the 2 sports. In this study, the most frequent method of injury in baseball was being hit by a pitched, thrown, or batted ball. This may be because children younger than 10 years have slower reflexes, less coordination, reduced ability to pitch accurately, and greater fear of being hit by the ball. ${ }^{32}$ Football coaches reported to researchers that they had difficulty with definition-of-injury compliance, specifically recording minor bruises and abrasions during games. Football teams generally had more players $(25+)$ participating in games, with offensive and defensive teams continually moving on and off the field. This made tracking injuries difficult for coaches. Football injuries may have been underreported in this study. 


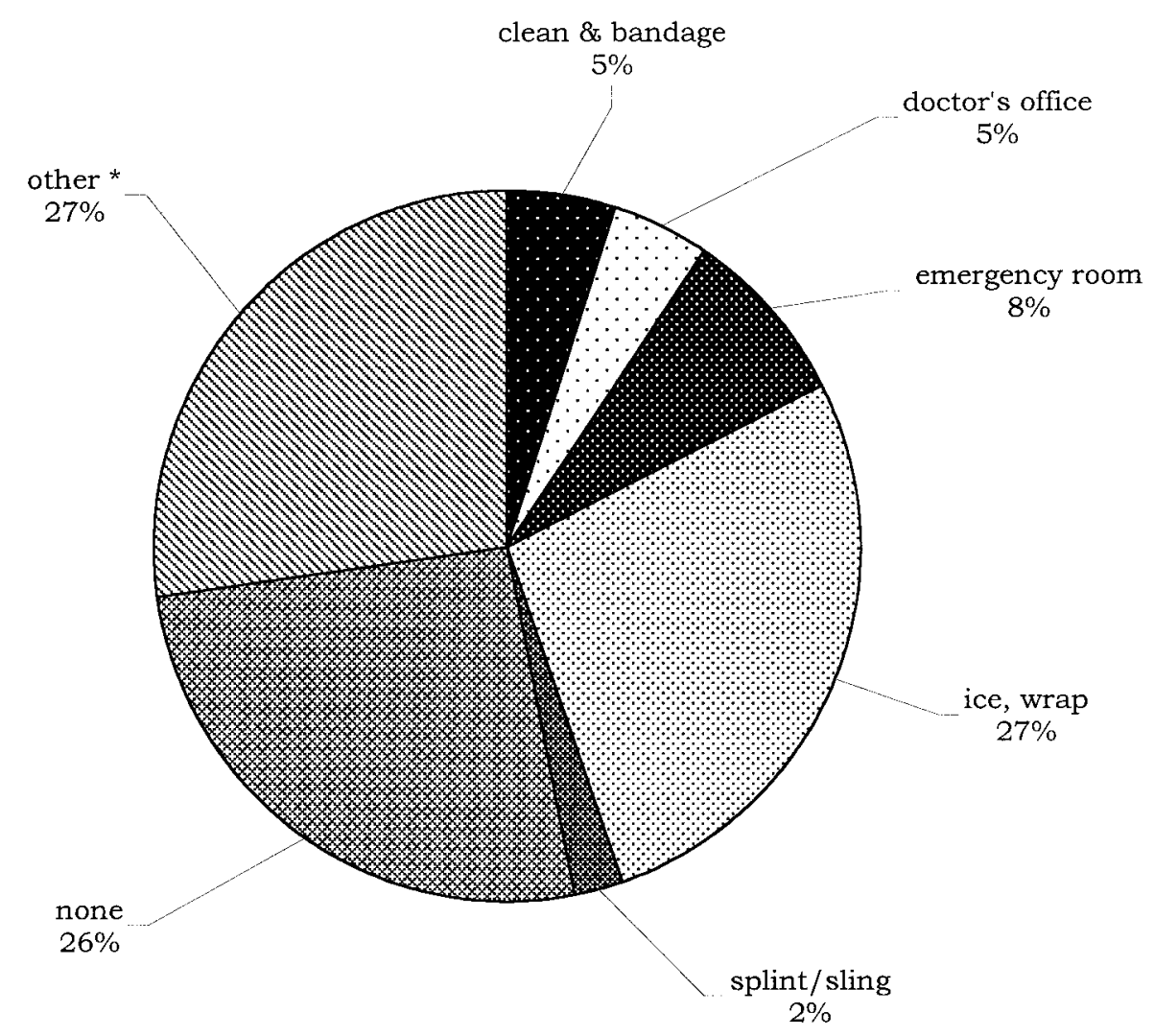

* rest, comfort, massage, padding, taping

Fig 5. Care given across sports.

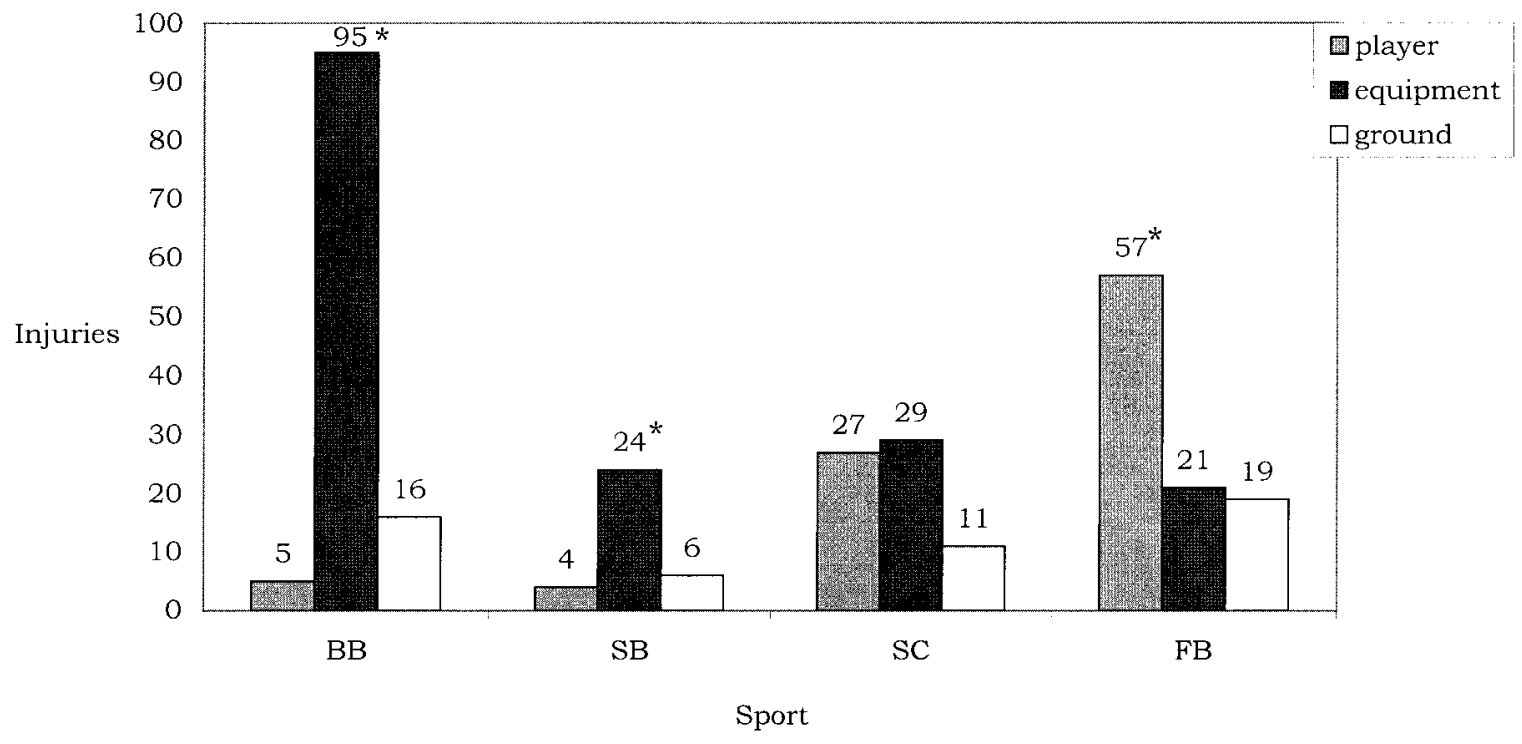

$* \mathrm{p}<.05$

Fig 6. Method of contact injury across sports.

Soccer

The injury rate for soccer was 2 per 100 AEs. This was the highest rate of any sport in this study. We believe that this can be attributed to reporting factors. In intramural and indoor leagues at this age level, play often stopped for even the most minor injury, allowing coaches to record data in compliance with the broad definition of injury. Most of the soccer coaches were also online, which enhanced researcher-coach communication throughout the study and increased reporting compliance.

Soccer divisions showed different injury frequencies, with indoor soccer showing more injuries than intramural or travel teams. This finding agrees with 
those of the American Academy of Pediatrics' Committee on Sports Medicine and Fitness study on Injuries in Youth Soccer ${ }^{33}$ and is attributable to the confined environment of the game and the indoor hard floor surfaces.

Lower extremity injuries were the most frequent for soccer teams in this study. Similar anatomic injury pattern data were reported by the Committee on Sports Medicine and Fitness, American Academy of Pediatrics for youth ages 5 to $23 .{ }^{33}$

\section{Game Versus Practice Injury Rates}

Across sports in this study, the injury rate for games was significantly higher than the injury rate for practices except for softball, in which there were more game injuries but not significantly more (Table $3)$. This result does not reflect the game versus practice injury rate ratio found in adolescents except in high school soccer. ${ }^{15}$ Other high school-based studies $2,16,19$ showed more acute injuries or a greater injury rate during practices than during games. At the high school level, there are consistently more practices than games during the season, creating more exposure to injury risk. This game-to-practice ratio was true only for football in this study. In addition, practices were not well attended across sports in this study, whereas games were usually full-roster events, increasing the injury risk at games.

\section{Injury Risk \\ FITS}

The FITS for football is 4 to 7 times higher than for the other sports (Fig 3). This was an expected result considering that football is a collision sport whose players have 2 to 3 times more AEs to injury than baseball, softball, or soccer players (Table 2). Injury studies with adolescent subjects found that football showed higher injury frequencies than other high school sports. $2,9,11,19,34,35$ In this study, the injury risk in football reflected the injury risk for adolescents in the sport.

\section{Maturation}

Each sport in this study had age and weight requirements that were closely followed, especially in football. Although we recognized that there were great variations in size and maturation in 10- to 13-year-olds, relating Tanner stages to injuries was beyond the scope of this study. Tanner factors need to be considered when developing and interpreting injury studies with this age group.

One of the unexpected findings in this study was that children ages 8 to 10 were injured more frequently than older (ages 11-13) or younger (ages 5-7) players in baseball and in football. In both sports, game parameters changed as players made the transition from the youngest, lightest teams (5- to 7-yearolds) to the next level of play. The change from rookie or T-ball to regulation Little League play required greater strength and endurance as field size increased and innings lengthened. Pitchers were now peers, not coaches, and sliding into bases was permitted. In football, there were similar changes in field size and length of playing time as players made the transition from the first level of participation (7-9 years, 98 pounds) to the second level (10-11 years, 112-125 pounds). The football FITS for 10- to 11-yearolds in this study population was 19; for 7- to 9-yearolds was 5, and for 12- to 13-year-olds was 14 . In contrast, Goldberg et $\mathrm{al}^{36}$ found that youth football participants in heavier weight divisions were injured more frequently than those in the lighter weight divisions. We agree that heavier, faster players generate a larger impact force and that injury risk would increase for those teams. However, sports skills such as sliding into a base, visual perception of the speed and trajectory of a ball, and eye-hand coordination are achieved through playing experience and physical maturation. Our results suggest that future injury studies consider player experience as well as size and maturity when analyzing injury rates or frequencies for 7- to 13-year-olds.

\section{Return to Play}

Each sport in this study had specific return-to-play guidelines in its charter. Our observation showed poor enforcement of these guidelines across sports, with individual coaches using their own standards for player clearance after time-lost injuries including fractures and concussions. Because proper management of musculoskeletal injuries for this age group is vital to normal growth and development, premature return to sport not only can increase the risk of reinjury but also can result in life-long consequences. Enforcement of return-to-play guidelines after mild traumatic brain injury injuries is vital to prevent second impact syndrome. ${ }^{37,38}$ Additional research is needed to determine whether second impact syndrome is significant even at this age level.

\section{Degree of Injury \\ Definition}

Although the injury survey tool used for this study indirectly assessed injury severity by using time lost from participation as a measure (Fig 1A, left), coaches did not consistently track and report these data throughout the season. To have some idea of the degree of injuries reported, we changed indicators from time lost to type of injury to define degree. We considered acute injuries that resulted in fractures, dislocations, or concussions as serious and considered all other acute injuries as less serious. Future injury studies for this age group need to have clearly defined severity indicators to determine when immediate interventions are needed for injury prevention.

\section{Overuse Injuries}

Although overuse injuries can result in serious sequelae for skeletally immature subjects, we did not attempt to track this type of injury because the degree of coach training needed to recognize microtrauma in players was beyond the scope of this study. Research is needed to determine age- and sport-specific data on this type of injury. 
Implications for Sports Medicine Professionals

Thirty-seven injuries across sports required emergency department or physician office visits. The discharge diagnoses for 22 of these injuries $(62.8 \%)$ was sprain, strain, or contusion. Although these types of injuries can be serious in children, in most cases they could be managed by certified trainers without incurring costs of emergency department or doctor visits.

\section{Study Limitations}

\section{Definition-of-Injury Compliance}

Compliance with the definition of injury proved difficult for most participating coaches. The broad definition required reporting injuries that would normally have been acknowledged only briefly, such as minor scrapes, bumps, and bruises. Football and baseball coaches found it difficult to comply with the broad definition of injury as shown by consistent discrepancies between the injuries that coaches reported and injuries recorded by our direct observation of the same events. These reporting discrepancies were greater for football than for baseball and affected injury rates as discussed previously.

\section{Reporting Compliance and Response Rates}

Participating community coaches all were volunteers who were responsible for every aspect of their team's performance and safety, including skills training, equipment, parental involvement, transportation, fundraising, playing time, and first aid during events. Although we designed the survey tool in a check-off format for ease of completion, it was still a time burden for coaches to complete and return data weekly.

Response rates varied across sports depending on how frequently coaches were contacted by researchers, how often league representatives offered positive reinforcement to participate or to continue participation in the study, and how much assistance coaches had with other aspects of team management. Baseball coaches responded with injury survey information for $73 \%$ of all actual events, softball coaches reported on $30 \%$ of all actual events, soccer coaches reported on $69 \%$ of all actual events, and football coaches reported on $85 \%$ of all actual events. Incentives included in the scope of this study did not adequately compensate coaches for their time, although weekly communication did increase the response rate considerably.

\section{Incomplete Reporting}

Data collected from 3 injury survey categoriestype of injury (Fig 4), care given (Fig 5), and method of injury (Fig 6) - are representative of this study population. However, we did not use them for comparison with other studies or for statistical analysis because reporting for those areas was completed on only $35 \%$ of the returned surveys.

\section{Recommendations for Modifications}

Injury surveillance for youth sports is gaining momentum as an important step toward formulating injury prevention methods, including teaching coaches the skills required to prevent injuries. ${ }^{39}$ However, establishing patterns of injuries, taking preventive measures, and evaluating equipment and coaching modifications may take years. In addition to the objective findings of this study, our direct observations of community sports through 2 seasons showed areas in which immediate modifications could reduce injury risk. Some of these modifications are under the direct control of youth sports leagues and can be implemented immediately through partnerships with local trainers, hospitals, physicians, and allied health professionals. Other safety modifications, specifically, field conditions, may be the physical and financial responsibility of municipalities and/or school systems making them subject to additional processes before they can be implemented.

The first recommendation is that youth sports leagues provide and require first aid training for coaches. Training could be done by sports medicine professionals and include recognition and immediate response to head, neck, and spine injuries as well as heat-related illnesses. A sports-specific emergency plan as outlined by National Athletic Trainers' Association ${ }^{40}$ should be included in these instructional sessions. Each coach should have a stocked first aid kit for all events. The second recommendation is that youth sports leagues have clear, enforceable returnto-play guidelines for concussions, neck and back injuries, fractures, and dislocations. The third recommendation is that baseball and softball leagues consider the injury prevention potential of face guards on batting helmets.

Additional factors that have an impact on injury risk to children, such as field conditions including turf and other playing surfaces, appropriate field size and drainage, lighting, and fencing, may not be as amenable to adjustment because of ownership, maintenance, and economic limitations. Condition and availability of equipment is directly under league control, but funding is often a limiting factor.

\section{Additional Research for Injury Prevention Strategies}

Injury surveillance studies using $\mathrm{AE}$ data and a uniform definition of injury are needed for this age group to detect patterns or trends for injury frequency, injury severity, anatomic injury sites, and mechanisms of injury. Expanded research questions could investigate whether injury patterns for children mirror those in adolescents/young adults, how Tanner staging affects injury rates, whether experienced or inexperienced players sustain more injuries within specific age/weight categories, or whether coach first aid training has any effect on reducing injury rates. The definition of injury in future studies should be narrow to focus on significant injuries but not so narrow that acute overuse injuries, which have the potential for serious long-term effects, are excluded.

\section{CONCLUSION}

This study showed that baseball had a higher injury rate than football. However, given the classifi- 
cation of football as a collision sport, the high number of AEs per player, the FITS score, and the percentage of injuries considered serious, youth football rather than baseball should be a priority for injury studies. Data from these studies reveal injury patterns and should guide health professionals in establishing uniform medical coverage policies for football even at this age level.

\section{ACKNOWLEDGMENTS}

This project was supported by a grant from the School of Education, University of Pittsburgh.

We thank John Powell, PhD, for advice on injury survey format and data analysis and Susan D. Geyer for injury survey design. The study would not have been possible without the patience and cooperation of the administrators and coaches from Pittsburgh BIG League, Dynamo Youth Soccer, the Northside Saints, LincolnLarimer, and Morningside Youth Football Associations. We thank them all.

\section{REFERENCES}

1. Arnheim D, Prentice W. Essentials of Athletic Training. 4th ed. Boston, MA: WCB/McGraw; 1999

2. Patel DR, Nelson TL. Sports injuries in adolescents. Med Clin North Am. 2000;844:983-1007

3. Wells M, Bell G. Concerns on Little League elbow. J Athletic Training. 1995;30:249-253

4. Zito M. The adolescent athlete: musculoskeletal update. J Orthop Sports Phys Therapy. 1983;5:20-25

5. Micheli LJ. Sports injuries in children and adolescents. Questions and controversies. Clin Sports Med. 1995;143:727-745

6. Maffuli N, Baxter-Jones A. Common skeletal injuries in young athletes. Sports Med. 1995;19:137-149

7. Outerbridge AR, Micheli LJ. Overuse injuries in the young athlete. Clin Sports Med. 1995;143:503-515

8. van Mechelin W. The severity of sports injuries. Sports Med. 1997;243: $176-180$

9. Koester MC. Youth sports: a pediatrician's perspective. J Athletic Training. 2000;354:466-470

10. International Federation of Sports Medicine/World Health Organization Ad Hoc Committee on Sports and Children. Consensus statement on "Organized Sports for Children." National Youth Sports Safety Committee Newsletter. Sidelines; 1998

11. Buckley S. Sports injuries in children. Curr Opin Pediatr. 1994;6:80-84

12. Muscari M. Preventing sports injuries. Am J Nurs. 1998;987:58-60

13. Roemmich JN, Rogol AD. Physiology of growth and development. Clin Sports Med. 1995;143:483-502

14. Levy MI. Formulation and sense of the NAIRS athletic injury surveillance system. Am J Sports Med. 1988;16(suppl):S132-S133

15. Powell JW. National High School Athletic Injury Registry. Am J Sports Med. 1988;16(suppl):S134-S135

16. Weaver NL, Mueller FO, Kalsheek WD, Bowling JM. The North Carolina high school athletic injury study: design and methodology. Med Sci Sports Exerc. 1999;311:176-182

17. Grollman LF, Irrgang JJ, Dearwater SR. In search of comparable high school sports injury data: Pennsylvania Athletic Trainers' Society, Inc Injury Reporting System (PIRS). J Athletic Training. 1995(suppl):S39

18. Aaron DJ, Laporte RE. Physical activity, adolescence and health: an epidemiological perspective. Exerc Sports Sci Rev. 1977;25:391-405

19. Beachy GKAC, Martinson M, Olderr TF. High school sports injuries: a longitudinal study at Punahou School 1988 to 1996. Am J Sports Med. 1997;25:675-681

20. Gallagher SS, Finison K, Guyer B, Goodenough S. The incidence of injuries among 87,000 Massachusetts children and adolescents: results of the 1980-91 statewide childhood injury prevention program surveillance system. Am J Public Health. 1984;74:1340-1346

21. Marchi AG, Di Bello D, Messi G, Gazzola G. Permanent sequelae in sports injuries: a population based study. Arch Dis Child. 1999;814: 324-328

22. Tweelar M, Verstappen FT, Hudson A. Is prevention of sports injuries a realistic goal? A four year prospective investigation of sports injuries among physical education students. Am J Sports Med. 1996;244:528-534

23. Mueller FO, Marshall MW, Kirby DP. Injuries in Little League baseball from 1987 through 1996. Physician Sports Med. 2001;297:41-48

24. Bijur PEAT, Harel Y, Overpeck MD, Jones D, Scheidt PC. Sports and recreation injuries in US children and adolescents. Arch Pediatr Adolesc Med. 1995;1499:1009-1016

25. Powell JW, Barber-Foss KD. Traumatic brain injury in high school athletics. JAMA. 1999;282:958-963

26. de Loes M. Exposure data. Why are they needed. Sports Med. 1997;24: 172-175

27. Finch CF. An overview of some definitional issues for sports injury surveillance. Sports Med. 1997;243:157-163

28. Lindenfeld TN, Noyes FR, Marshall MT. Components of injury reporting systems. Am J Sports Med. 1988;16(suppl):S69-S80

29. Meeuweisse WH, Love EJ. Athletic injury reporting. Development of universal systems. Sports Med. 1997;243:184-204

30. van Mechelin W. Sports injury surveillance systems: one size fits all? Sports Med. 1997;243:164-168

31. Wallace R. Application of epidemiologic principles to sports injury research. Am J Sports Med. 1988;16(suppl):S22-S24

32. American Academy of Pediatrics, Committee on Sports Medicine and Fitness. Risk of injury from baseball and softball in children. Pediatrics. 2001;107:782-784

33. American Academy of Pediatrics, Committee on Sports Medicine and Fitness. Injuries in youth soccer: a subject review. Pediatrics. 2000;105: $659-661$

34. Hergenroeder AC. Prevention of sports injuries. Pediatrics. 1998;101: 1057-1063

35. Stanitski CL. Pediatric and adolescent sports injuries. Clin Sports Med. 1997;164:613-633

36. Goldberg B, Rosenthal PP, Nicholas JA. Injuries in youth football. Physician Sports Med. 1984;128:122-130

37. Cantu RC. Head and spine injuries in youth sport. Clin Sports Med. 1995;143:517-532

38. Perriello VA, Barth JT. Sports concussions: coming to the right conclusions. Contemp. Pediatr. 2000;2:132-139

39. Janda D. Sports injury surveillance has everything to do with sports medicine. Sports Med. 1997;243:169-171

40. Anderson JC, Courson RW, Kleiner DM, McLoda TA. National Athletic Trainers' Association Position Statement: Emergency Planning in Athletics. I Athletic Training. 2002;371:99-104 